\title{
Rainwater retention capacity of green roofs in subtropical monsoonal climatic regions: a case study of Taiwan
}

\author{
C. F. Fang \\ Department of Landscape Architecture, \\ National Chin-Yi University of Technology, R.O.C.
}

\begin{abstract}
This study investigates how roof substrate and vegetation affect rainwater retention. The investigated parameters are lightweight substrate ratio, substrate depth, precipitation and vegetation type. A planting box was placed on the roof of a building to simulate a green roof. Scheduled artificial rainfall was used to test the rainwater retention capacity of various substrates, substrate depths and plant types. The experimental results indicate that precipitation, substrate depth, substrate ratio and vegetation type affect the rainwater retention capacity of green roofs. The rainwater retention rate is inversely proportional to precipitation intensity; that is, about $87-100 \%$ of rainwater is retained for light rain, $62-84 \%$ for moderate rain and only $26-33 \%$ for heavy rain. Different plants have different abilities to retain rainwater. In this study, Dianella ensifolia cv. 'Silvery Stripe' and Schefflera arboricola have the best water retention rates of 37-100\%. Of the total amount of rainwater retained, the substrate accounts for $77-98 \%$ and vegetation accounts for $2-23 \%$. In the sub-tropical region, the green roof water retention rate is roughly $30 \%$ of the total storm precipitation $(100 \mathrm{~mm})$. Thus, using a green roof is an effective strategy for managing urban stormwater.
\end{abstract}

Keywords: lightweight substrate, precipitation, rainwater retention, substrate depth, substrate ratio.

\section{Introduction}

As water cannot penetrate paved surfaces, rainwater cannot percolate into the ground, leading to significant surface runoff that can increase river erosion and 
cause flooding. However, if urban roof tops were transformed into green roofs, municipal surface runoffs can be effectively reduced [6].

Green roofs can retain about $60-100 \%$ of rainwater $[1,4,6,7,13]$. Kolb [4] showed that $45 \%$ of rainfall can be recycled by green roofs. Additionally, green roofs can delay the runoff by about $95 \mathrm{~min}$ to 4 hours. The primary factors affecting the water retention capacity of green roofs include substrate depth $[6,7]$, precipitation [6] and vegetation [14]. Most studies of the water-retention capability of green roofs are conducted in Germany, Sweden and the US, nations located in temperate zones.

Annual precipitation in Taiwan, which is located in a sub-tropical zone, is as high as $2400 \mathrm{~mm}$. Every year, 3-4 typhoons bring massive amounts of precipitation $(500-1400 \mathrm{~mm})$ within a short period. The climate in Taiwan is markedly different from the temperate climate; thus, green roof research results for temperate zones cannot be applied to Taiwan. If studies address the climate, substrates and vegetation in Taiwan, experimental results for green roof rainwater retention rainwater will be valuable references when developing policies to manage urban stormwater.

This study examines the effectiveness of green roof substrates and vegetation on rainwater retention in sub-tropical Taiwan. Substrate mixing ratio, substrate depth, precipitation and vegetation are the parameters investigated. Boxes containing substrate and vegetation were placed on a rooftop; a known quantity of water was administered to simulate precipitation for determining the rainwater retention capacity of the planting box. The experimental results will be a reference for managing stormwater surface runoff.

\section{Methods}

\subsection{Rooftop planting box}

A plastic planting box, $60 \mathrm{~cm}(\mathrm{~L}) \times 48 \mathrm{~cm}(\mathrm{~W}) \times 16 \mathrm{~cm}(\mathrm{H})$, had drain holes drilled in its bottom surface. Starting at the bottom, the box contained a drainage and water-retention layer, non-woven material, lightweight substrate and vegetation (Figures 1,2).

\subsection{Substrates ratio}

Lightweight substrates are used to reduce the weight load on a roof. Three lightweight substrates, i.e., perlite, vermiculite and peat moss, are mixed at a 1:1:1 volume ratio. This mixture is then blended with sandy soil to form the following final substrates: $60 \%$ lightweight substrate; $80 \%$ lightweight substrate; and $100 \%$ lightweight substrate.

The $60 \%$ lightweight substrate contains $60 \%$ lightweight substrate and $40 \%$ sandy soil with a 20:20:20:40 volume ratio of perlite, vermiculite, peat moss and sandy soil, respectively.

The $80 \%$ lightweight substrate contains $80 \%$ lightweight substrate and $20 \%$ sandy soil with a 26.7:26.7:26.7:20 volume ratio of perlite, vermiculite, peat moss and sandy soil, respectively. 


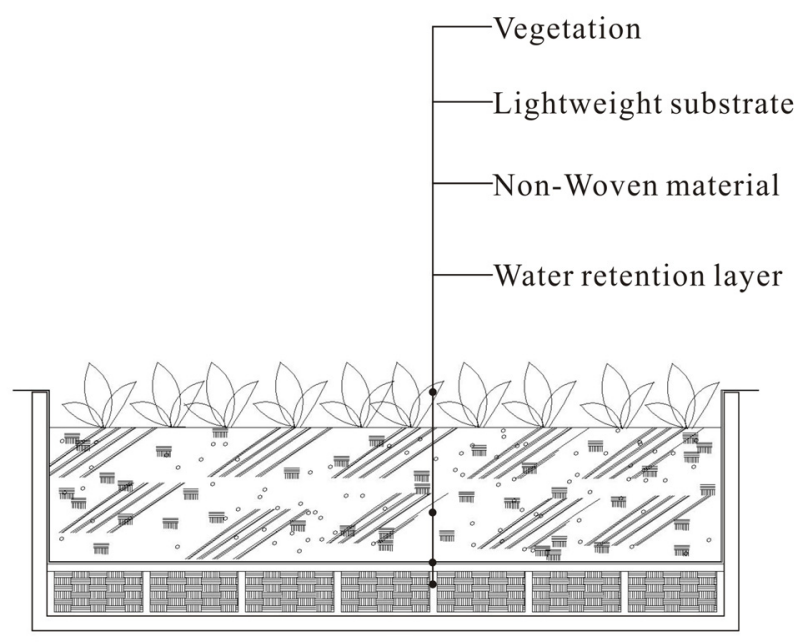

Figure 1: $\quad$ Schematic diagram showing a cross-section of the green roof.

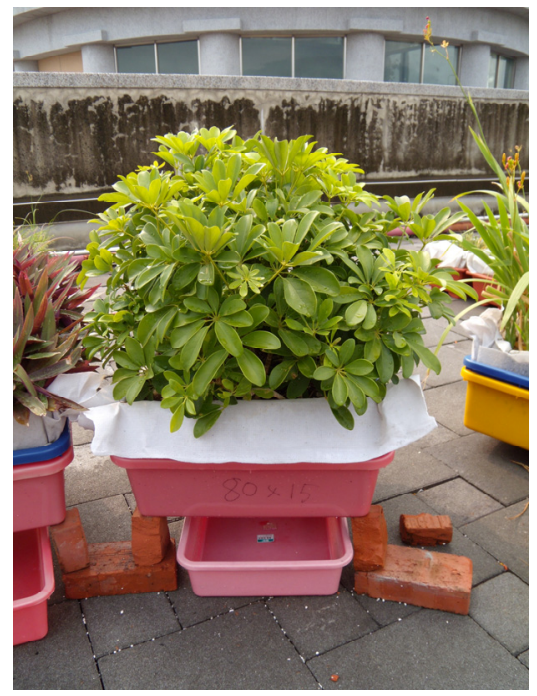

Figure 2: The experiment on rainwater retention capacity.

The 100\% lightweight substrate contains 100\% lightweight substrate with a 33.3:33.3:33.3 volume ratio of perlite, vermiculite and peat moss, respectively.

Additionally, the influence of substrate depth on rain retention is studied using substrate depths of $5 \mathrm{~cm}, 10 \mathrm{~cm}$ and $15 \mathrm{~cm}$. 


\subsection{Water sprinkling rates}

According to Taiwan's Central Weather Bureau, $10 \mathrm{~mm}$ of precipitation is considered light rain, $30 \mathrm{~mm}$ is considered moderate rain and $100 \mathrm{~mm}$ is considered heavy rain. These precipitation amounts are converted based on planting box area into water sprinkling amounts of $2880 \mathrm{cc}, 7000 \mathrm{cc}$ and 28800 cc to simulate light rain, moderate rain and heavy rain, respectively.

\subsection{Rain retention capacity}

Water is sprinkled at $50 \mathrm{~cm}$ above the planting box for $30 \mathrm{~min}$. The watered box is then undisturbed for 1 day; the quantity of water collected in the collection box is recorded as drained water. The rainwater retention capacity is the difference between the amount of water sprinkled and that drained. The water retention ratio is the water retention capacity divided by precipitation. The experiment is conducted on the roof of an administrative building on the campus of National Chin-Yi University of Technology, central Taiwan.

\subsection{Experimental type}

The experiment was carried out in two phases. The objective of the first phase is to study the influence of substrate ratio, substrate depth and precipitation on rainwater retention capacity. The objective of the second phase is to examine the influence of various vegetation types on rainwater retention capacity.

\subsubsection{Experiment I}

The parameters evaluated in this experiment are substrate ratios $(60 \%, 80 \%$ and $100 \%$ lightweight substrate), substrate depths $(5,10$ and $15 \mathrm{~cm})$ and precipitation

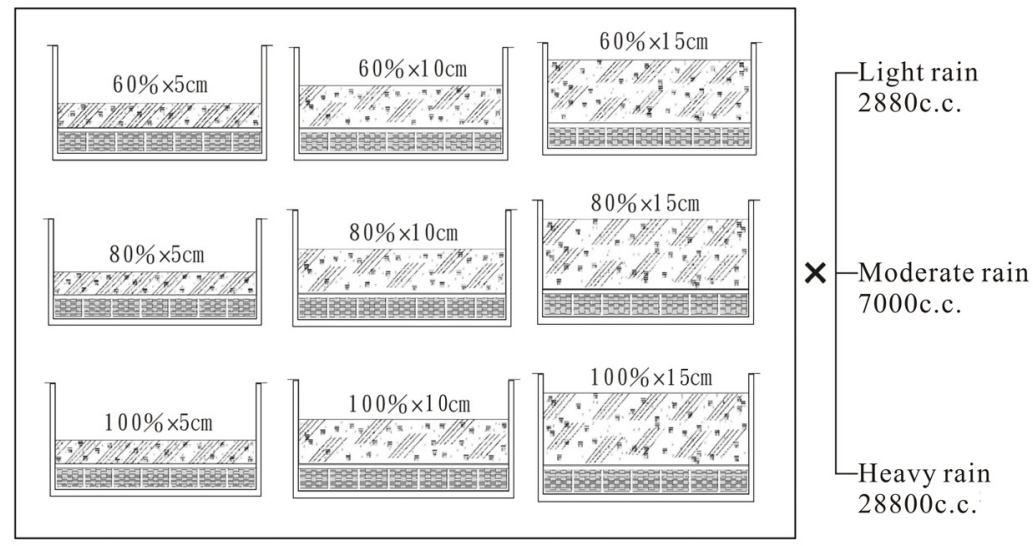

Figure 3: Schematic diagram of planting boxes with various substrate depths and lightweight substrate. 
intensities (light, moderate and heavy rain) for a total of 27 combinations. Each combination is repeated 8 times; the average of 8 datasets is used. The experiment was carried out during April-October 2009. Figure 3 shows experimental parameter combinations. All substrates are cured and dried naturally 1 week prior to use in the experiment.

\subsubsection{Experiment II}

Five vegetations types, Schefflera arboricola, Belamcanda chinensis, Wedelia trilobata, Dianella ensifolia cv. 'Silvery Stripe,' and Zoysia spp., are planted in $80 \%$ lightweight substrate at a depth of $15 \mathrm{~cm}$ under simulated light, moderate and heavy rain. Each condition is repeated 8 times and the average is used in evaluation. All substrates and vegetation are cured and dried naturally 1 week prior to use in the experiment.

\section{Experimental results}

\subsection{Precipitation and substrate}

The rainwater retention capacity was relatively low under light rain and relatively high under heavy rain (Figure 4), indicating that the substrate rainwater retention capacity is proportional to precipitation; water retention during heavy rain is almost triple that during light rain. However, when the ratio of water retention to total precipitation is considered, the substrate can retain $87-$ $100 \%$ of total precipitation for light rain, $62-84 \%$ for moderate rain and only 26 $33 \%$ for heavy rain. The $60 \%$ lightweight substrate has the best rainwater retention capacity, followed by $80 \%$ lightweight substrate (Figure 4 ).

Table 1: The ANOVA of rain water retention from precipitation, substrate ration and substrate depth.

\begin{tabular}{|c|c|c|c|c|c|}
\hline Source & $\mathbf{S}$ & df & MS & $\mathbf{F}$ & Sig. \\
\hline Precipitation & $1.1 \mathrm{E}+09$ & 2 & $5.6 \mathrm{E}+08$ & 889.741 & $.000^{* * *}$ \\
\hline Substrate ration & $1.3 \mathrm{E}+07$ & 2 & 6259934 & 9.891 & $.000^{* * *}$ \\
\hline Substrate depth & $2.1 \mathrm{E}+07$ & 2 & $1.0 \mathrm{E}+07$ & 16.378 & $.000^{* * *}$ \\
\hline $\begin{array}{l}\text { Precipitation* } \\
\text { Substrate ration }\end{array}$ & 5322755 & 4 & 1330689 & 2.103 & .082 \\
\hline $\begin{array}{l}\text { Precipitation* } \\
\text { Substrate depth }\end{array}$ & 9387963 & 4 & 2346991 & 3.708 & $.006^{* *}$ \\
\hline $\begin{array}{l}\text { Substrate ration* } \\
\text { Substrate depth }\end{array}$ & 3369769 & 4 & 842442 & 1.331 & .260 \\
\hline $\begin{array}{c}\text { Precipitation* } \\
\text { Substrate ration* } \\
\text { Substrate depth }\end{array}$ & 5703501 & 8 & 712938 & 1.126 & .347 \\
\hline Residual & $1.2 \mathrm{E}+08$ & 189 & 632902 & & \\
\hline Total & $7.4 \mathrm{E}+09$ & 216 & & & \\
\hline
\end{tabular}



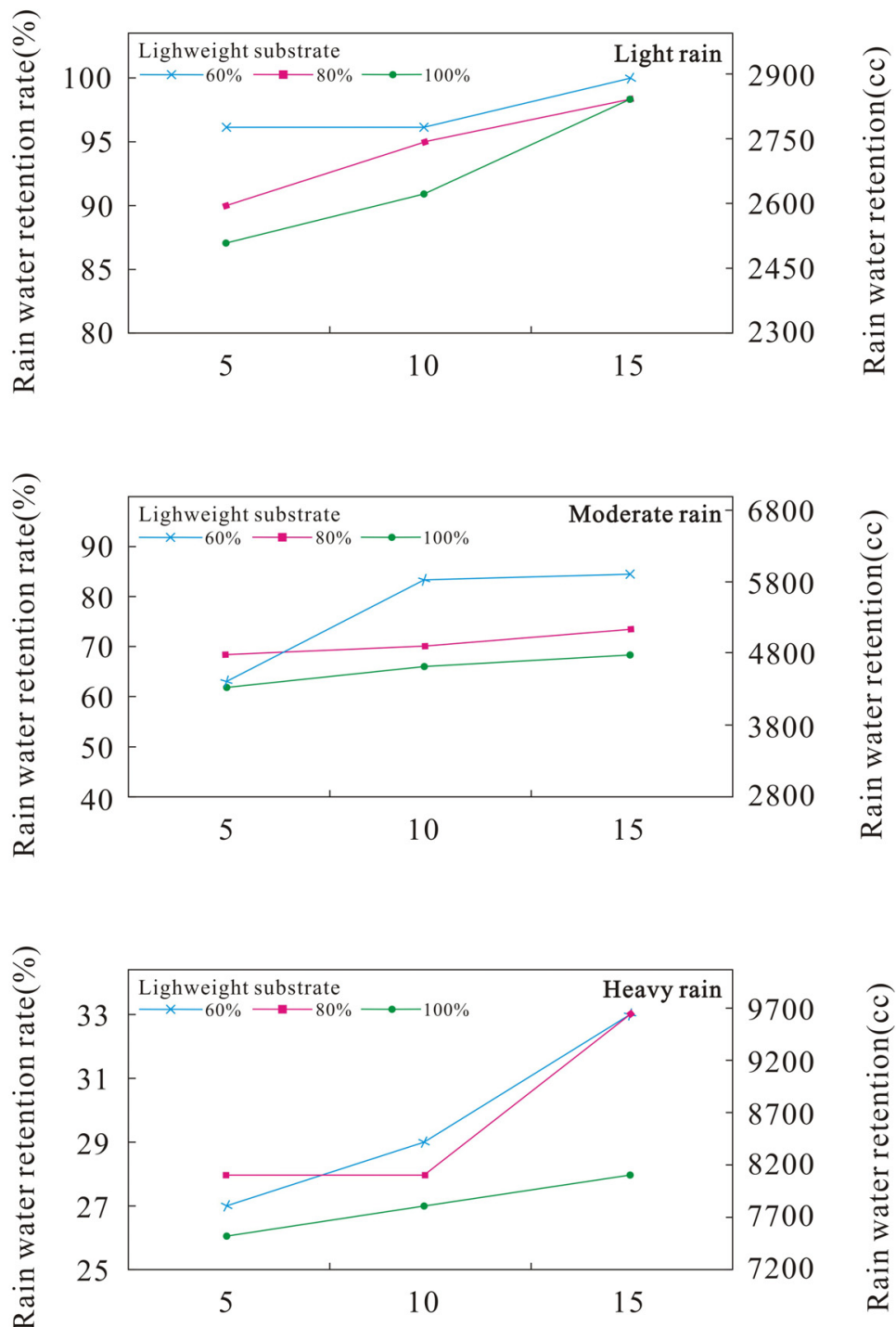

Substrate depth $(\mathrm{cm})$

Figure 4: The rainwater retention capacity for various substrates under $10 \mathrm{~mm}$ of precipitation for light rain, $30 \mathrm{~mm}$ for moderate rain and $100 \mathrm{~mm}$ for heavy rain. 

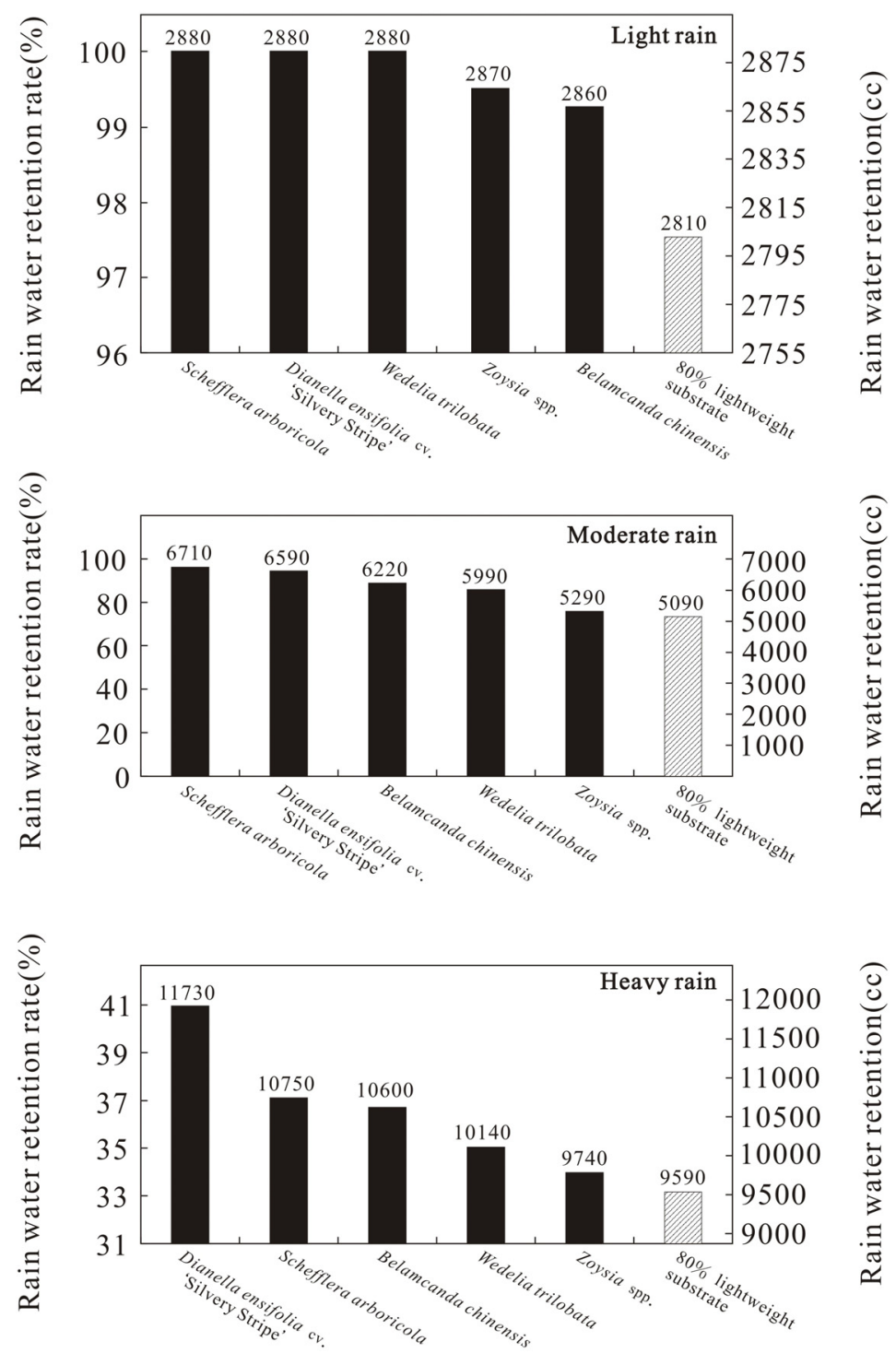

Species

Figure 5: The percentage of rainwater retention for vegetation types (light rain, $10 \mathrm{~mm}$; moderate rain, $30 \mathrm{~mm}$; and heavy rain, $100 \mathrm{~mm}$ ). 
A three factorial ANOVA is applied identify the important factors for rainwater retention by green roofs. The dependent factor is rainwater retention and independent factors are precipitation, substrate depth and substrate ratio. Precipitation, substrate depth and substrate ratio are the significant parameters influencing rainwater retention capacity (Table 1).

\subsection{Green roof with different vegetation types}

The green roof using a 15-cm-deep layer of $80 \%$ lightweight substrate retains $99-100 \%$ of rainwater under light rainfall $(10 \mathrm{~mm}), 76-96 \%$ of rainwater under moderate rain $(30 \mathrm{~mm})$ and $34-41 \%$ of rainwater under heavy rain. Dianella ensifolia cv. 'Silvery Stripe' and Schefflera arboricola retain water best, rainwater and Zoysia spp. has the worst rainwater retention rate (Figure 5).

The substrate accounts for $77-98 \%$ and the vegetation accounts for $2-23 \%$ of total rainwater retained. Hence, the substrate is an extremely important parameter for retaining rainwater.

\section{Discussion}

Experimental results reveal that heavy precipitation is associated with the highest amount of rainwater retained (Figure 4). However, the water retention rate is lowest for heavy rainwater. This is because precipitation exceeds the total retention capacity, an observation in agreement with that made by Nicholaus et al. [8]. Combining the data obtained by Nicholaus et al. [8] and that acquired by this study, to discuss the relationship between precipitation and rainwater retention rate of ecological roof (Figure 6). Although the precipitation in the study by Nicholaus et al. [8] differs from that in this research, similar negative relationships were found between substrate retention capacity and precipitation. Nicholaus et al. [8] reported a rainwater retention of 38.9-99.3\%, rainwater whereas that in this study was $26-87 \%$ rainwater. The lower rainwater retention rate in Taiwan is likely caused by that fact that temperate regions receive $2-10$ $\mathrm{mm}$ of per precipitation, whereas sub-tropical Taiwan receives $10-100 \mathrm{~mm}$ of per precipitation, exceeding the capacity of soil to retain water.

Figure 4 shows the linearly proportional relationship between substrate depth and rainwater retention effectiveness. A deep substrate layer has more volume for storing rainwater than a shallow layer rainwater. Nicholaus et al. [8] reported that water retention capacity increased as substrate depth increased. Some researchers have considered the substrate depth also influence vegetation growth, drought stress and drought tolerance [2, 7, 8]. Hence, a deep substrate is recommended to enhance vegetation growth and rainwater retention capacity. We suggest that substrate depth should exceed $15 \mathrm{~cm}$ for a green roof to be effective in retaining rainwater in sub-tropical regions subject to considerable amounts of precipitation.

Experimental results obtained by this study show that the substrate is more important that the vegetation species to rainwater retention efficiency. Monterusso et al. [7] made the same observation. Because water is directly 


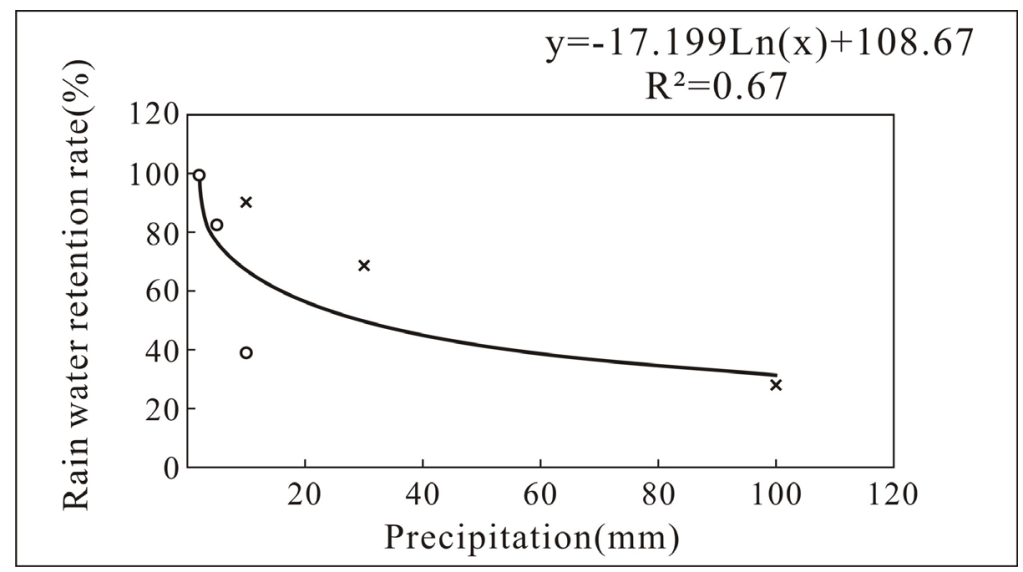

Figure 6: Regression analysis on the relationship between the logarithmic rainwater retention quantity and precipitation. $\mathrm{O}$ : Data obtained by Nicholaus et al. [8] for a 6-cm-deep substrate without vegetation. $\mathbf{X}$ : Data from this study for a 5-cm-deep substrate without vegetation.

retained in the substrate void and vegetation absorbs water through absorption and evaporation, the rate of water retention for vegetation is slower than that for a substrate. Although vegetation is not as effective as substrates in retaining rainwater, vegetation prevents soil loss and solar radiation impacting green roofs $[3,5,8]$, provides habitat, reduce the heat by evaporation $[9,11]$, mitigates air pollution [10] and elevate the amenity [14].

Most studies in temperate regions used $<10 \mathrm{~mm}$ of precipitation and obtained rainwater retention percentages of $40-100 \%$ [7, 12]. In this study water retention capacity for light rain of $10 \mathrm{~mm}$ precipitation was also $99.5-100 \%$. Although the rainwater retention rate of a green roof is only $34-41 \%$ for heavy rain, this water retention rate is still valuable when managing urban stormwater.

High-intensity rainfall during the monsoon season in sub-tropical regions is a significant challenge for managing municipal stormwater surface runoff. Although green roofs cannot absorb all rainwater, green roofs mitigate the adverse impact of stormwater and, thus, are an effective option for managing municipal stormwater surface runoff. Additionally, green roofs are more costeffective than other techniques for managing stormwater.

\section{Conclusions and recommendations}

The effectiveness of using green roofs for retaining rainwater was assessed in this study using substrate ratio, substrate depth, precipitation and vegetation as parameters.

1. Precipitation, substrate depth, substrate ratio and vegetation affect the rainwater retention capacity of a green roof. 
2. The rainwater retention capacity of a substrate is proportional to precipitation. However, the rainwater retention rate is inversely proportional to precipitation because substrates have a limited number of voids for storing water. Once the rainwater retention capacity is reached, a substrate cannot retain additional water.

3. Substrate ratio is proportional to rainwater retention efficiency; the $60 \%$ lightweight substrate has the highest rainwater retention rate, followed by $80 \%$ and $100 \%$ lightweight substrates.

4. The green roof with a substrate layer $15 \mathrm{~cm}$ deep retained $98-100 \%$ of precipitation for light rain, $68-84 \%$ for moderate rain and $28-33 \%$ for heavy rain. Water retention was $77-98 \%$ by the substrate and $2-23 \%$ by vegetation. Thus, substrate was the most important factor for rainwater retention and vegetation type was of minor importance.

5. In sub-tropical regions, green roofs can retain $28-33 \%$ of rainwater during heavy rain $(100 \mathrm{~mm})$. Although all stormwater is not absorbed, green roofs are an effective strategy for managing urban stormwater. Additionally, green roofs are inexpensive to build as they utilize unused rooftops.

\section{References}

[1] DeNardo, J. C., Jarrett, A. R., Manbeck, H. B., Beattie, D. J. \& Berghage, R. D., Stormwater mitigation and surface temperature reduction by green roofs. Transactions of the ASAE, 48, pp. 1491-1496, 2005.

[2] Durhman, A. K. D., Rowe, D. B. \& Rugh, C. L., Effect of substrate depth on initial growth, coverage, and survival of 25 succulent green roof plant taxa. HortScience, 42, pp. 588-595, 2007.

[3] Eumorfopoulou, E. \& Aravantions, D., The contribution of a planted roof the thermal protection of buildings in Greece. Energy and Buildings, 27, pp. 29-36, 1998.

[4] Kolb, W., Good reasons for roof planting: Green roofs and rainwater. Acta Horticulturae, 643, pp. 295-300, 2004.

[5] Kumar, R. \& Kaushik, S. C., Performance evaluation of green roof and shading for thermal protection of buildings. Energy and Buildings, 27, pp. 1505-1511, 2005.

[6] Mentens, J., Raes, D. \& Hermy, M., Green roof as a tool for solving the rainwater runoff problem in the urbanized $21^{\text {st }}$ century? Landscape and Urban Planning, 77, pp. 217-226, 2006.

[7] Monterusso, M. A., Rowe, D. B., Rugh, C. L. \& Russell, D. K., Runoff water quantity and quality from green roof systems. Acta Horticulturae, 639, pp. 369-376, 2004.

[8] Nicholaus, D., Van Woert, D., Rowe, B., Andresen, J. A., Rugh, C. L., Fernandez, R. T. \& Xiao, L., Green roof stormwater retention: effects of roof surface, slope, and media depth. Journal of Environmental Quality, 34, pp. 1036-1044, 2005.

[9] Onmura, S., Matsumoto, M., \& Hokoi, S., Study on the evaporative cooling effect of roof lawn gardens. Energy and Buildings, 33, pp. 635-666, 2001. 
[10] Peck, S., Callaghan, C., Bass, B. \& Kuhn, M., Greenback from Green Roofs: Forging a new industry in Canada, Toronto, 1999.

[11] Takakura, T., Kitade, S. \& Goto, E. Cooling effect of greenery cover over a building. Energy and Buildings, 31, pp. 1-6, 2000.

[12] Thompson, W., Grass-roofs movement in landscape architecture. Landscape Architects, 88, pp. 47-51, 1998.

[13] VanWoert, N. D., Rowe, D. B., Andresen, J. A., Rugh, C. L., Fernandez, R. T. \& Xiao, L., Green roof stormwater retention: Effect of roof surface, slope, and media depth. Journal of Environmental Quality, 34, pp. 10391044, 2005.

[14] Villarreal, E. L. \& Bengtsson, L. Response of a Sedum green-roof to individual rain events. Ecological Engineering, 25, pp. 1-7, 2005. 